\title{
Anomalous transfer phenomenon of carbon nanotube in the blend of polyethylene and polycarbonate
}

\author{
Rujirek Wiwattananukul, Yuki Hachiya, Takaomi Endo, \\ Shogo Nobukawa and Masayuki Yamaguchi*
}

School of Materials Science, Japan Advanced Institute of Science and Technology

1-1 Asahidai, Nomi, Ishikawa 923-1292 JAPAN

\footnotetext{
*Corresponding author. E-mail address: m_yama@jaist.ac.jp (Masayuki Yamaguchi)

Phone: +81-761-51-1621

Fax: $+81-761-51-1621$
} 


\begin{abstract}
A contradict interphase transfer of multi-walled carbon nanotubes (MWCNT) is detected in the immiscible polymer pair of polyethylene (PE) and polycarbonate (PC). When laminated sheets composed of PE with MWCNTs and PC are annealed in the molten state of both polymers, MWCNTs are found to move from PE to PC. This transfer phenomenon is originated from the difference in the interfacial tension with the aid of Brownian motion. On the contrary, MWCNTs prefer to reside in the PE phase in the blend of PE, PC and MWCNTs, even when MWCNTs are first dispersed in PC. This result indicates that MWCNTs transfer from PC to PE. The opposite direction of the transfer is attributed to the PE molecules being adsorbed on the surface of MWCNTs, which are generated during mixing.
\end{abstract}

Keywords: Electrical Properties; Interphase; Thermoplastic resin; Carbon fibre;

\title{
Laminates
}


Wiwattananukul et al., 3

\section{Introduction}

Carbon nanotubes (CNTs) have been investigated in many research fields ever since their discovery by Iijima in 1991 [1]. Due to their high aspect ratio (100-1000) and specific surface area, the electrical and mechanical properties of a polymeric material can be improved by adding CNTs [2-4]. Based on the above characteristics, it is appropriate to employ CNTs as a conductive filler in polymer composites for many applications in the manufacturing such as electrostatic dissipation, interference shielding, and so on [5-7]. Of course, the electrical properties of polymer composites are affected by the dispersion of CNTs in the material, therefore it is important to understand and control the CNT dispersion $[8]$.

Sumita et al. described the concept of double percolation, in which the amount of carbon blacks (CBs) is beyond the critical value for percolation in one continuous phase of an immiscible blend $[9,10]$. This method makes it possible to prepare a conductive composite with a small amount of CBs. Sumita et al. also revealed that CBs selectively reside in polyethylene (PE) phase in the blend of PE and poly(methyl methacrylate) (PMMA), although PE is a non-polar polymer [10]. Furthermore, $\mathrm{Wu}$ et al. found that the addition of PE reduces the percolation threshold of the composite with vapor-grown carbon fibers (VGCFs) in PMMA [11]. They explained that it is attributed to the self-assembled conductive network constructed by selective adsorption of PE on the end part of the VGCF filament. Later, they explained that this phenomenon is attributed to the flexibility of PE chains, which leads to the preferential adsorption at the rough ends of VGCF by entropic favor [12]. Similarly, Pötschke et al. prepared a conductive blend using polycarbonate (PC) and PE with MWCNTs and found that MWCNTs act as a bridge between two polymers by the adsorption of chain ends [13]. Though, Mamunya et al. reported that the selective localization of conductive fillers in an immiscible polymer blend can be predicted by the interfacial tension 
between polymers and conductive fillers [14]. Typically, CNTs immigrate from a polymer with high interfacial tension to another with low interfacial tension through the boundary between the phases, because CNTs show high surface tension $(45 \mathrm{mN} / \mathrm{m})$ [15]. Besides, Gubbels et al. demonstrated that the selective localization of CBs at the interphase between $\mathrm{PE}$ and polystyrene (PS) in the co-continuous blend can greatly reduce the content of $\mathrm{CBs}$ required for the percolation threshold [16]. This selective localization occurs at the specific balance of interfacial tension among polymers and fillers.

Recently, the imprinting technique of nanofillers from one polymer to another has been developed to modify the surface properties of polymers [17-20]. Doan et al. conducted the annealing procedure using laminated sheets composed of pure PE and polypropylene (PP) containing nanofibers of poly(butylene terephthalate) (PBT) [19]. They found that PBT fibers are transferred from molten PP to PE, which results in the surface-modified PE sheet after separation of the laminated sheets. Similarly, nanofibers of polytetrafluoroethylene (PTFE) in a molten poly(lactic acid) (PLA) are transferred from PLA to PP during the annealing procedure, although PTFE does not transfer from PP to PLA [19]. These results indicate that the localization phenomenon is attributed to the compatibility with nanofillers. Furthermore, they reported that silica nanoparticles preferentially migrate from poly(styrene-co-butadiene) (SBR) to poly(butadiene) (BR) phase during annealing beyond their glass transition temperatures [20]. Nevertheless, the migration from BR to SBR does not occur, demonstrating that the interfacial tension between silica and BR is lower than that between silica and SBR, i.e., the compatibility between silica and a rubber is the main driving force for the transfer.

In the previous paper in our research group [21], it was found that the interphase diffusion of MWCNTs from PP to PC occurs during the annealing treatment of laminated sheets composed of PP/MWCNT and PC, leading to a conductive film of PC with a 
significantly small amount of MWCNTs. In contrast, the transfer is not detected at all from PC to PP. The results directly indicate that the interfacial tension between PC and MWCNT is lower than that between PP and MWCNT. Since the Brownian motion is required for the interphase diffusion, the annealing time and temperature are critical conditions for the transfer.

In this study, however, a contradict phenomenon of the MWCNT transfer from PC to PE phase was detected during melt-mixing process. Considering that MWCNTs move from $\mathrm{PE}$ to $\mathrm{PC}$ in laminated sheets composed of PE/MWCNTs and PC, these results should be noted. This study will provide the useful information on the material design using PE and carbon fillers with understanding of the driving force of PE adsorption on the fillers. Furthermore, it will be applicable to obtain high-performance polymer blends reinforced by CNTs. Since the enhancement of mechanical properties, especially rigidity, is greatly required in the field of automobiles and aircrafts, intense interest has been focused on composites with CNTs. In these applications, for example, CNTs should be localized in a matrix of rubber-modified plastics with sea-island structure.

\section{Experimental}

\subsection{Materials}

The polymers used in this study were commercially available bisphenol A polycarbonate (PC) (Panlite L-1225Y, Teijin Co., Ltd., Japan, MFR = 11 [g/10 min]) and high-density polyethylene (PE) (HJ590N, Japan Polyethylene Corp., MFR = 40 [g/10 min]). The number- and weight-average molecular weights, characterized by a size exclusion chromatograph (SEC) (Tosoh Corp., HLC-8020) using chloroform as an eluent, of PC are 1.9 $\times 10^{4}$ and $9.7 \times 10^{4}$, respectively, as a polystyrene standard. Moreover, $M_{n}$ and $M_{w}$ of PE were also characterized by SEC using 1,2,4-trichlorobenzene at $140{ }^{\circ} \mathrm{C}$ and found to be 0.87 
Wiwattananukul et al., 6

$\times 10^{4}$ and $4.9 \times 10^{4}$, respectively as a polyethylene standard. The density of PE is $960\left[\mathrm{~kg} / \mathrm{m}^{3}\right]$ at room temperature.

MWCNTs were produced by a catalytic chemical vapor deposition method using a floating reactant method and subsequent thermal treatment up to $2,600{ }^{\circ} \mathrm{C}[22,23]$. Typical diameters of the MWCNTs are ranging from 40 to $80 \mathrm{~nm}$ as shown in Fig. 1, while the lengths are between 10 and $20 \mu \mathrm{m}$. The density is approximately $2,300\left[\mathrm{~kg} / \mathrm{m}^{3}\right]$.

\section{[Fig.1]}

Two types of composites with $20 \mathrm{wt} \%$ of multi-walled carbon nanotubes (MWCNTs), i.e., PC/MWCNT and PE/MWCNT, were kindly provided by Hodogaya Chemical Co., Ltd. (Japan) as a pellet form.

\subsection{Sample preparation}

Pure PC and its composite with $20 \mathrm{wt} \%$ of MWCNTs were dried at $120{ }^{\circ} \mathrm{C}$ for $8 \mathrm{~h}$ in a vacuum oven before processing.

A composite of PC/MWCNT (80/20) was mixed with pure PE in the molten state using a $30 \mathrm{cc}$ internal mixer at $250{ }^{\circ} \mathrm{C}$ for $10 \mathrm{~min}$ at a blade rotation speed of $50 \mathrm{rpm}$. The blend ratio of PC/MWCNT and PE was 80:20 in weight fraction, i.e., PC/MWCNT/PE = 64/16/20. In addition, another blend composed of pure PC and pure PE at a blend ratio of $76 / 24(=64 / 20)$ was also prepared under the same condition without MWCNTs. The obtained samples were compressed into flat sheets with a thickness of $1 \mathrm{~mm}$ using a laboratory compression-molding machine (Table-type test-press, Tester Sangyo Co., Ltd., Japan) at 200 ${ }^{\circ} \mathrm{C}$ under $10 \mathrm{MPa}$ for $3 \mathrm{~min}$.

Flat sheets of PE, PC, PE/MWCNT (80/20) and PC/MWCNT (80/20) were also prepared using the compression-molding machine at $200{ }^{\circ} \mathrm{C}$ under $10 \mathrm{MPa}$ for $3 \mathrm{~min}$. Then, the sheets with $1 \mathrm{~mm}$ thickness were subsequently cooled at $25^{\circ} \mathrm{C}$. The transfer experiments 
in the laminated sheets were conducted by placing a pure PC sheet on a PE/MWCNT (80/20) sheet $(\mathrm{PC}-\mathrm{PE} / \mathrm{MWCNT})$. After the annealing treatment at $250{ }^{\circ} \mathrm{C}$ for $10 \mathrm{~min}$, the sheets were immediately cooled and separated. The same experiment was performed using a pure PE sheet and a PC/MWCNT (80/20) sheet (PE - PC/MWCNT). This procedure was also described in detail in our previous paper [21].

\subsection{Measurements}

The flat sheets of PC/PE and PC/MWCNT/PE with a thickness of about $1 \mathrm{~mm}$ were immersed in chloroform to remove PC fraction at room temperature for three days. Then, the insoluble part in chloroform was immersed into hot-xylene to remove PE fraction at $140{ }^{\circ} \mathrm{C}$ for $6 \mathrm{~h}$. The chloroform and xylene solutions with dissolved polymers were collected and subsequently dried up to characterize the dissolved parts. Furthermore, the insoluble part was dried and weighed to determine the soluble fraction $S$, defined by equation (1).

$$
S=\frac{w_{i}-w_{f}}{w_{i}} \times 100
$$

where $w_{i}$ is the initial weight of the sample and $w_{f}$ is the weight of the dry sample after immersion.

In addition, the MWCNT distribution on the surface of the insoluble part in chloroform and xylene and the surface of cryogenically fractured PC/MWCNT/PE was observed by a scanning electron microscope (SEM) (Hitachi Ltd., S4100). The surfaces of the separated PC and PE sheets at laminated experiments were also examined. Prior to the observation, all specimens were coated with Pt-Pd by a sputter coating machine.

The infrared (IR) spectra of pure PC and the dissolved part of the samples after extraction were measured by a Fourier-transform infrared spectroscopy (FT-IR) analyzer (Perkin Elmer Inc., Spectrum 100). 
Electrical resistivity was measured on the surface of the separated sheets using constant-voltage supplied resistivity meters (MCP-HT450 and MCP-T610, Mitsubishi Chemical Analytech Co., Ltd., Japan). The measurements were performed five times for each sample at room temperature, and the average value was calculated.

\section{Results and Discussion}

\subsection{MWCNT transfer in laminated sheets}

The laminated sheets composed of a pure polymer and the other polymer with MWCNTs (20 wt\%), i.e., PE - PC/MWCNT and PC - PE/MWCNT, were annealed at $250{ }^{\circ} \mathrm{C}$ for 10 min to study the transfer behavior of MWCNTs. After quenching, the sheets were able to be separated without any difficulty because of the immiscible nature of PE and PC. The surface resistivity of the separated PC sheet is found to be $10^{6} \Omega /$ sq., which is significantly lower than that of pure PC $\left(>10^{15} \Omega /\right.$ sq. $)$. This result indicates that MWCNTs move from PE to PC during the applied annealing procedure. However, the surface resistivity of the separated PE sheet after annealing is higher than $10^{15} \Omega /$ sq., which is the same level as that for pure PE. It suggests that MWCNT transfer does not occur from PC to PE because of the difference in the compatibility of MWCNT with polymers.

SEM observation was performed to characterize the MWCNT distribution on the surface of the separated polymer sheets. As seen in Fig. 2(a), MWCNTs are dispersed on the PC surface, corresponding to the electrical resistivity measurement. In contrast, the MWCNT transfer is not detected from PC to PE as shown in Fig. 2(b).

\section{[Fig.2]}

The transfer phenomenon is explained by interfacial tension between the CNT and the polymer components, which can be estimated by the Girifalco-Good equation $[24,25]$ as follows; 
Wiwattananukul et al., 9

$$
\Gamma=\gamma_{1}+\gamma_{2}-2 \sqrt{\gamma_{1} \gamma_{2}}
$$

where $\Gamma$ is the interfacial tension between components and $\gamma_{i}$ is the surface free energy of $i$-th component.

It is known that the surface free energies of $\mathrm{PE}$ and $\mathrm{PC}$ at $200{ }^{\circ} \mathrm{C}$ are 25 and 32 $\mathrm{mN} / \mathrm{m}$, respectively [26]. Further, the surface free energy of MWCNTs has been reported by several researchers and was found to be larger than $45[\mathrm{mN} / \mathrm{m}][15,27,28]$. The interfacial tension between the polymer and MWCNT is calculated and listed in Table 1, assuming that surface free energy of MWCNT is $45[\mathrm{mN} / \mathrm{m}]$ [15].

\section{[Table I]}

It is clearly seen that the interfacial tension between PE and MWCNT is significantly higher than that between PC and MWCNT. Hence, the interphase diffusion of MWCNTs occurs only from PE to PC. The results obtained in this experiment correspond with the previous report [21].

\subsection{MWCNT transfer during melt-mixing}

The localization behavior of MWCNTs in an immiscible blend composed of PE and PC was studied using an internal mixer. In this study, MWCNTs were dispersed in PC at first $(\mathrm{PC} / \mathrm{MWCNT}=80 / 20)$. Then pure PE was added into the blend at $250{ }^{\circ} \mathrm{C}$ for $10 \mathrm{~min}$. After compression-molding of the obtained composite (PC/MWCNT/PE $=64 / 16 / 20)$ at $200{ }^{\circ} \mathrm{C}$, the sheet with $1 \mathrm{~mm}$ thickness was immersed into chloroform at room temperature for three days. The solution is shown in Fig. 3 with the reference samples, i.e., PC/MWCNT (80/20) and PC/PE (64/20) without MWCNTs.

\section{[Fig.3]}

In the case of PC/MWCNT, the solution is black. This is reasonable because MWCNTs are dispersed in the solution after PC is dissolved in the solvent. For the same 
reason, the solution of $\mathrm{PC} / \mathrm{PE}(64 / 20)$ is opaque due to the light scattering of dispersed $\mathrm{PE}$ particles. In contrast, the solution of PC/MWCNT/PE (64/16/20) is fairly transparent, although PC is fully dissolved into chloroform. It should be noted because the result suggests that MWCNTs are not dispersed in the PC phase in the blend. Furthermore, it is found from the weight measurement that the insoluble part is approximately $36 \mathrm{wt} \%$, which corresponds with the total amount of PE and MWCNT. Then the solution was filtrated to remove MWCNTs and/or PE by a filter paper. The filtrate solution was dried and subsequently compressed into a flat film. Thereafter, the film sample was characterized by FT-IR. It is demonstrated from the spectra in Fig. 4 that PC fraction is dissolved in chloroform.

\section{[Fig.4]}

Considering the weight measurement, PC fraction in PC/MWCNT/PE $(64 / 16 / 20)$ is completely dissolved in chloroform, although MWCNTs are barely dispersed in the solution. Therefore, it can be concluded that MWCNTs are dispersed in PE phase in the blend of PC/MWCNT/PE (64/16/20). In other words, MWCNT transfer occurs from PC to PE during mixing, which is completely opposite to that detected at the laminated sheets.

The fractured surface of the blend, i.e., PC/MWCNT/PE, is also studied by SEM, as shown in Fig. 5. The co-continuous phase-separated structure is detected, in which only one phase, i.e., PE, contains MWCNTs.

\section{[Fig.5]}

To clarify the mechanism of the contradictory results, the insoluble part in chloroform is immersed into hot-xylene. Prior to the experiment, it was confirmed that pure PE is totally dissolved into hot-xylene at the same experimental condition. However, the insoluble part in chloroform, i.e., PE/MWCNT, is not completely dissolved into hot-xylene. The weight of the remaining insoluble part in hot-xylene is $23.6 \mathrm{wt} \%$ of the original blend (PC/MWCNT/PE). The dissolved part in hot-xylene (12.4 wt $\%$ of the original blend) is PE, which is confirmed 
by FT-IR. Moreover, it should be noted that the solution is transparent as shown in Fig. 6, demonstrating that there are two types of PE; one is free from MWCNTs and the other is adsorbed on the MWCNT surface and forms network structure.

\section{[Fig.6]}

The surface morphology of the insoluble part after immersed in hot-xylene is demonstrated in Fig. 7. It is clearly seen that the shish-kebab structure, which must be PE crystals, is detected on MWCNTs. The result indicates that PE molecules adsorbed on the MWCNT surface are crystallized from MWCNTs because of the marked nucleation ability of MWCNTs as reported previously $[29,30]$.

\section{[Fig.7]}

These experimental results suggest that PE molecules are adsorbed on MWCNTs during melt-mixing, presumably with the aid of oxygen. In the rubber industry, it is well known that some molecules are adsorbed on carbon blacks, which are called "bound rubber" [31-33]. Although the detail mechanism of the present system is unclear, functional groups containing oxygen on the surface of MWCNTs are responsible for the reaction and/or adsorption. In fact, PE shows branching reaction with the aid of oxygen [34]. The MWCNTs covered by PE molecules are expelled from PC phase and move to PE because of high interfacial energy between PE and PC. Therefore, mixing condition will play an important role on the distribution of MWCNTs in PC/PE blends, which greatly affects the mechanical properties in the solid state. Although the selective adsorption of PE on VGCF and MWCNT was already reported [10-13], the present results are completely different from those of previous studies. In the case of the previous studies, PE molecules are absorbed on the rough edge of fibers owing to the flexibility of PE chains. In contrast, our results demonstrate that PE molecules can be absorbed even on the flat surface of the carbon fillers as shown in Fig. 1. This "in-situ surface modification" of MWCNTs will be available for the material design 
of CNT-reinforced multi-components systems, because CNTs can be localized in a specific phase, e.g., matrix in a blend with sea-island structure.

\section{Conclusion}

The interphase transfer of MWCNTs in the immiscible blend of PE and PC is studied by two methods; (1) annealing in the laminated sheets and (2) melt-mixing in the mixer. It is found that MWCNTs move from PE to PC during the annealing treatment in the laminated sheets. On the contrary, the interphase diffusion from PC to PE does not occur due to a large difference in the surface tension between PE and MWCNT.

In the case of melt-mixing, it is interesting to note that MWCNT transfer occurs from PC to PE, not from PE to PC, which has been confirmed by solvent immersion, FT-IR and SEM measurements. The contradict phenomenon is attributed to the strong adsorption of PE chains on the whole surface of MWCNTs, which will occur by the chemical reaction with the aid of oxygen during melt-mixing. The grafted PE chains on MWCNTs lead to the interphase transfer from PC to PE.

\section{Acknowledgements}

This work was promoted by COI program "Construction of next-generation infrastructure system using innovative materials" - Realization of safe and secure society that can coexist with the Earth for centuries - Supported by Japan Science and Technology Agency (JST). The authors also would like to express their gratitude to Hodogaya Chemical Co., Ltd. for their valuable advice and the kind supply of the samples employed in this study.

\section{REFERENCES}

[1] Iijima S. Jelical microtubules of graphitic carbon. Nature 1991;354:56-8. 
[2] Lau KT, Hui D. The revolutionary creation of new advanced materials-carbon nanotubecomposites. Composite Part B 2002;33:263-77.

[3] Pötschke P, Fornes TD, Paul DR, Rheological behavior of multiwalled carbon nanotube/polycarbonate composites. Polymer 2002;43:3247-55.

[4] Gardea F, Lagoudas DC. Characterization of electrical and thermal properties of carbon nanotube/epoxy composites. Composite Part B 2014;56:611-20.

[5] Ruoff RS, Lorents DC. Mechanical and thermal properties of carbon nanotubes. Carbon 1995;33:925-30.

[6] Ma PC, Siddiqui NA, Marom G, Kim JK. Dispersion and functionalization of carbon nanotubes for polymer-based nanocomposites: a review. Composite Part A 2010;41:1345-67.

[7] Rokni H, Milani AS, Seethaler RJ. 2D optimum distribution of carbon nanotubes to maximize fundamental natural frequency of polymer composite micro-beams. Composites Part B 2012;43:779-85.

[8] Ke K, Wang Y, Liu XQ, Cao J, Luo Y, Yang W, Xie BH, Yang MB. A comparison of melt and solution mixing on the dispersion of carbon nanotubes in a poly(vinylidene fluoride) matrix. Composites Part B 2012;43:1425-32.

[9] Sumita M, Sakata K, Asai S, Miyasaka K, Nakagawa H. Dispersion of fillers and the electrical conductivity of polymer blends filled with carbon black. Polym Bull 1991; 25:265-71.

[10] Sumita M, Sakata K, Hayakawa Y, Asai S, Miyasaka K, Tanemura M. Double percolation effect on the electrical conductivity of conductive particles filled polymer blends. Colloid Polym Sci 1992;270:134-9. 
[11] Wu G, Asai S, Sumita M. A self-assembled electric conductive network in short carbon fiber filled poly(methyl methacrylate) composites with selective adsorption of polyethylene. Macromolecules 1999;32:3534-6.

[12] Wu G, Asai S, Sumita M. Entropy penalty-induced self-assembly in carbon black or carbon fiber filled polymer blends. Macromolecules 2002;35:945-51.

[13] Pötschke P, Bhattacharyya AR, Janke A. Morphology and electrical resistivity of meltmixed blends of polyethylene and carbon nanotube filled polycarbonate. Polymer $2003 ; 44: 8061-9$.

[14] Mamunya YE. Morphology and percolation conductivity of polymer blends containing carbon black. J Macromol Sci Phys 1999;38:615-22.

[15] Nuriel S, Liu L, Barber AH, Wagner HD. Direct measurement of multiwall nanotube surface tension. Chem Phys Lett 2005;404:263-6.

[16] Gubbles F, Jerome R, Teyssie Ph, Vanlathem E, Deltour R, Calderome A, et al. Selective localization of carbon black in immiscible polymer blends: A useful tool to design electrical conductive composites. Macromolecules 1994;27:1972-4.

[17] Gates BD, Xu Q, Steward M, Ryan D, Willson CG, Whitesides GM, et al. New approaches of nanofabrication: molding, printing and other techniques. Chem Rev 2005; 105:1171-96.

[18] Nie Z, Kumacheva E. Patterning surfaces with functional polymers. Nature Materials 2008;7:277-90.

[19] Doan VA, Nobukawa S, Yamaguchi M. Localization of nanofibers on polymer surface using interface transfer technique. Composites Part B 2012;43:1218-23.

[20] Doan VA, Nobukawa S, OhtsuboS, Tada T, Yamaguchi M. Selective migration of silica particles between rubbers. J Polym Res 2013;20:145-50. 
[21] Yoon H, Okamoto K, Yamaguchi M. Carbon nanotube imprinting on a polymer surface. Carbon 2009;47:2840-6.

[22] Kim YA, Hayashi T, Endo M, Kaburagi Y, Tsukada T, Shan J, et al. Synthesis and structural characterization of thin multiwalled carbon nanotubes with a partially facetted cross section by a floating reactant method. Carbon 2005;43:2243-50.

[23] Chen J, Shan JY, Tsukada T, Munekane F, Kuno A, Matsuo M, et al. The structural evolution of thin multi-walled carbon nanotubes during isothermal annealing. Carbon $2007 ; 45: 274-80$.

[24] Adamson AW, Gast AP. Physical Chemistry of Surfaces. 6 ${ }^{\text {th }}$ ed., New York: Wiley;1997:348-78.

[25] Ross S, Morrison ID. Colloidal Systems and Interfaces. New York: Wiley;1998:657-67.

[26] Brandrup J, Immergut EH, Grulke EA, Bloch DR, editors. Polymer handbook. $4^{\text {th }}$ ed., New York:Wiley;1999:VI/521-5.

[27] Dujardin E, Ebbesen TW, Krishnan A, Trecy MM. Wetting of single shell carbon nanotubes. Adv Mater 1998;10:1472-5.

[28] Barber AH, Cohen SR, Wagner HD. Static and dynamic wetting measurements of single carbon nanotubes. Phys Rev Lett 2004;92:186103.

[29] Liang S, Wang K, Chen D, Zhang Q, Du R, Fu Q. Shear enhanced interfacial interaction between carbon nanotubes and polyethylene and formation of nanohybrid shish-kebabs. Polymer 2008;49:4925-9.

[30] Li L, Wang W, Laird ED, Li CY, Defaux M, Ivanov DA. Polyethylene/carbon nanotube nanohybrid shish-kebab obtained by solvent evaporation and thin-film crystallization. Polymer 2011;52:3633-8. 
[31] Lee BL, Singleton C. Experimental study of the relationship of processing to the morphology in blends of SBR and cis-Polybutadiene with carbon black. J Appl Polym Sci 1979;24:2169-83.

[32] Callan JE, Hess WM, Scott CE. Elastomer blends. Compatibility and relative response to fillers. Rubber Chem Technol 1971;44:814-37.

[33] Yurekli K, Krishnamoorti R, Tse MF, Mcelrath KO, Tsou AH, Wang HC. Structure and dynamics of carbon black-filled elastomers. J Polym Sci Part B 2001;39:256-75.

[34] Peacock AJ. Handbook of polyethylene structures, properties, and applications. New York: Marcel Dekker;2000:375-82.

\section{Figure Captions}

Fig. 1 SEM image of MWCNTs

Fig. 2 SEM images of (a) PC surface separated from PE/MWCNT (80/20) and (b) PE surface separated from PC/MWCNT (80/20) after annealing at $250{ }^{\circ} \mathrm{C}$ for $10 \mathrm{~min}$.

Fig. 3 Photographs of the immersion experiment in chloroform;
(a) PC/MWCNT (80/20), (b) PC/PE (64/20) and (c) PC/MWCNT/PE (64/16/20)

Fig. 4 Infrared spectra of insoluble parts in chloroform at room temperature for (a) $\mathrm{PC} / \mathrm{PE}$ (64/20) and (b) PC/MWCNT/PE (64/16/20).

In the figure, the spectra of pure PC and PE are also shown as references.

Fig. 5 SEM image of fractured surface of PC/MWCNT/PE (64/16/20).

Fig. 6 Photograph of the immersion experiment in hot-xylene at $140{ }^{\circ} \mathrm{C}$ for $6 \mathrm{hr}$ using the insoluble part in chloroform of PC/MWCNT/PE (64/16/20).

Fig. 7 SEM images of the surface of PC/MWCNT/PE after extracted by chloroform and hotxylene at different magnifications. 
Table 1 Interfacial tension $\Gamma$ between polymers and MWCNT

\begin{tabular}{ll}
\hline \multicolumn{2}{c}{$\Gamma(\mathbf{m N} / \mathbf{m})$} \\
\hline PC-PE & 0.431 \\
PC-CNT & 1.105 \\
PE-CNT & 2.918 \\
\hline
\end{tabular}

Rujirek et al., Table 1 


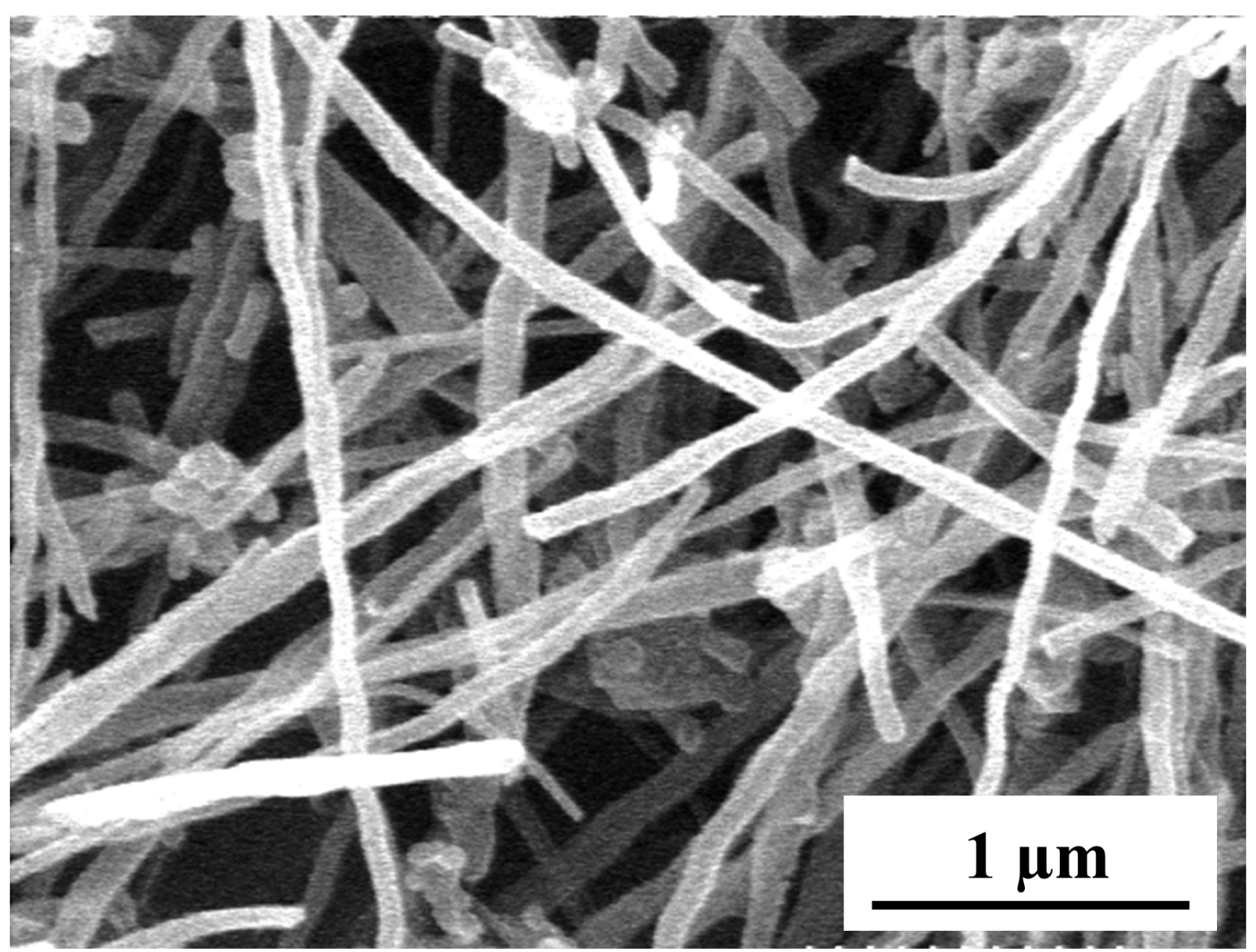

Rujirek et al., Fig. 1 


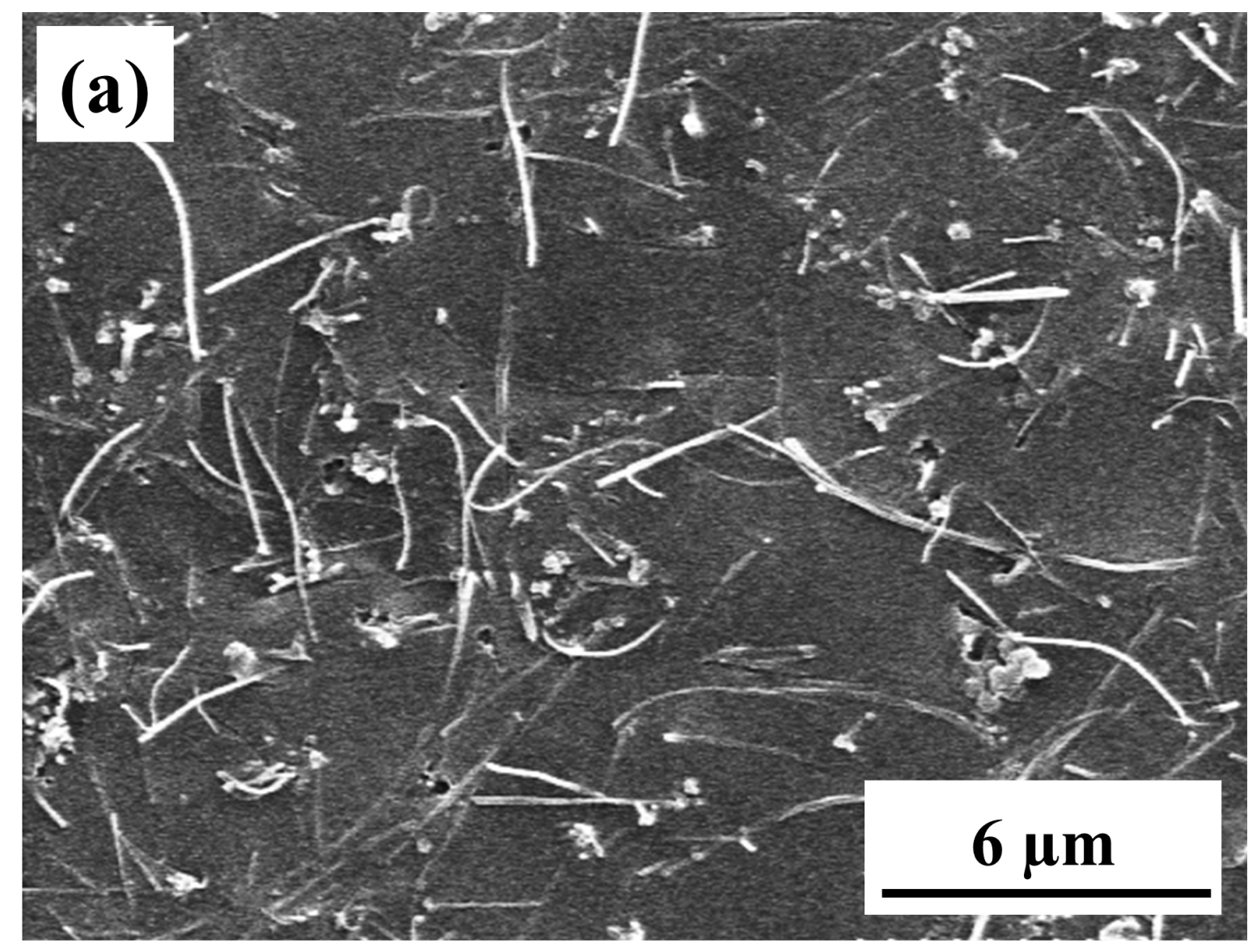

Rujirek et al., Fig. 2(a) 


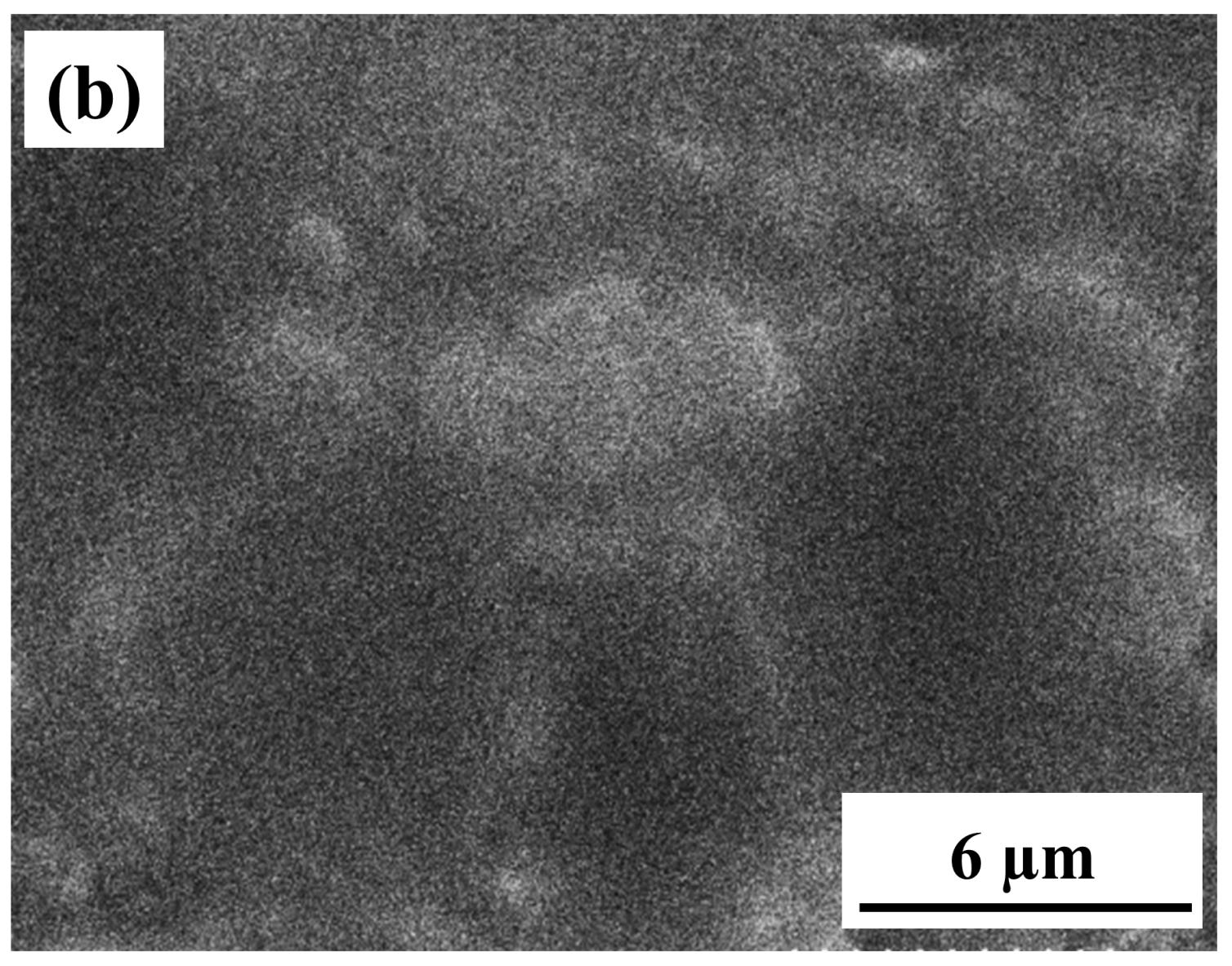

Rujirek et al., Fig. 2(b) 
(a)

Rujirek et al., Fig. 3(a) 


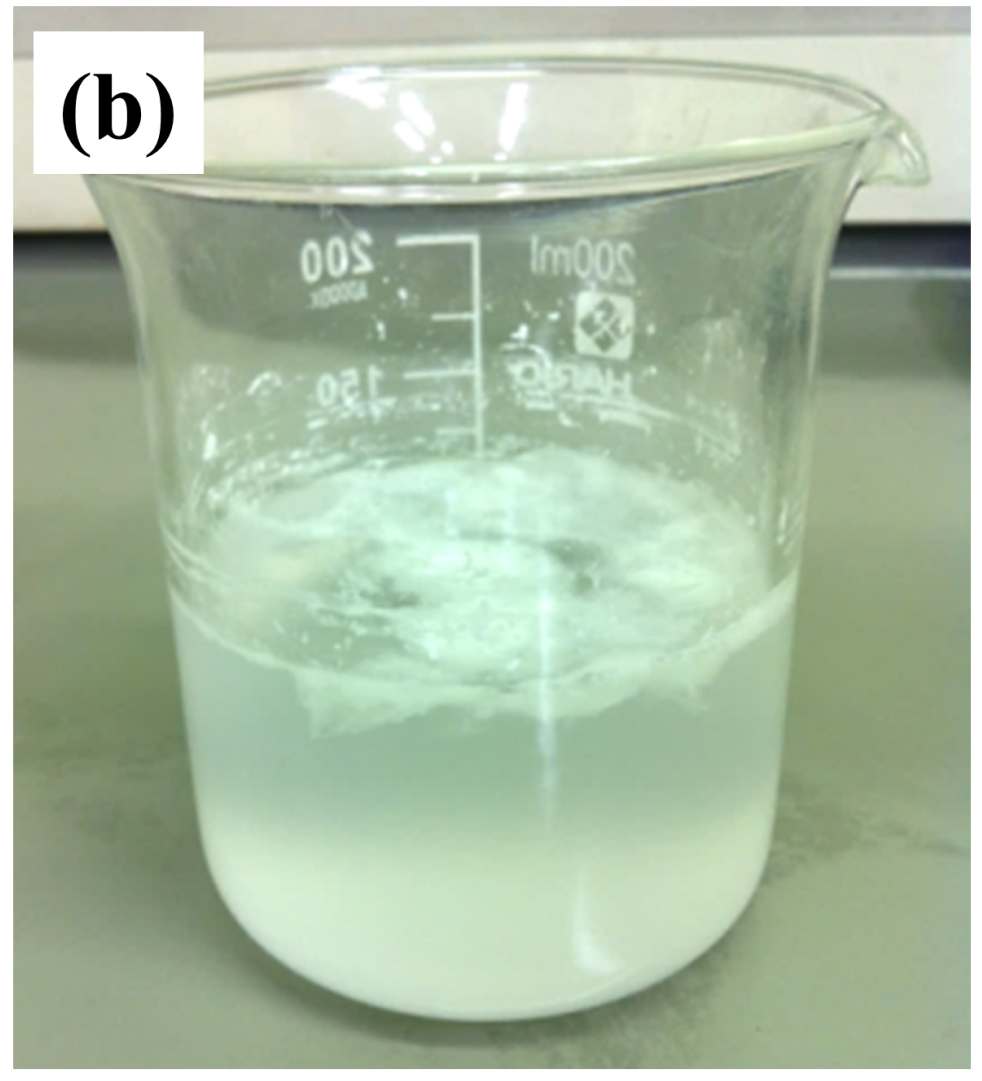

Rujirek et al., Fig. 3(b) 


\section{(c)}

Rujirek et al., Fig. 3(c) 


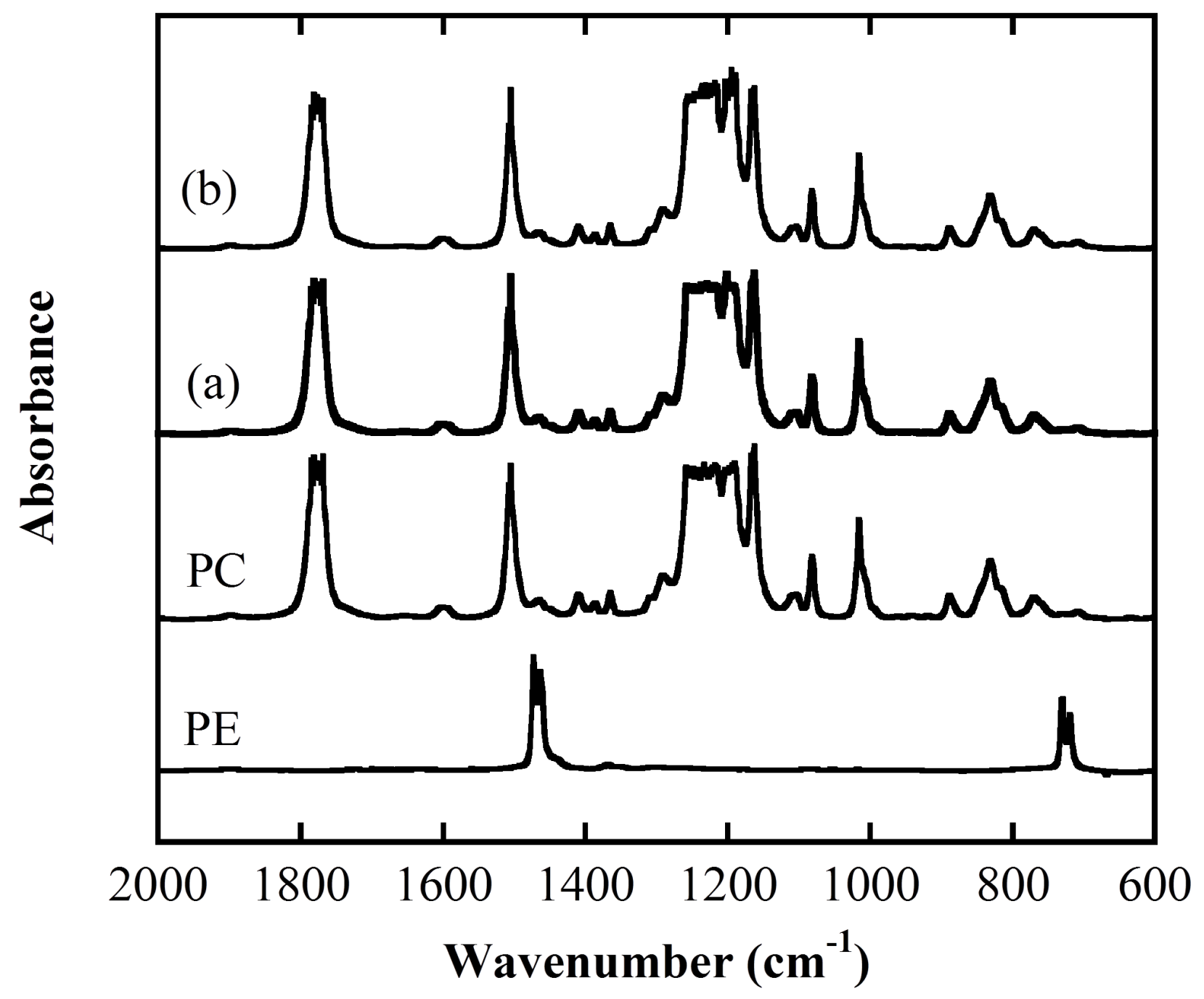

Rujirek et al., Fig. 4 


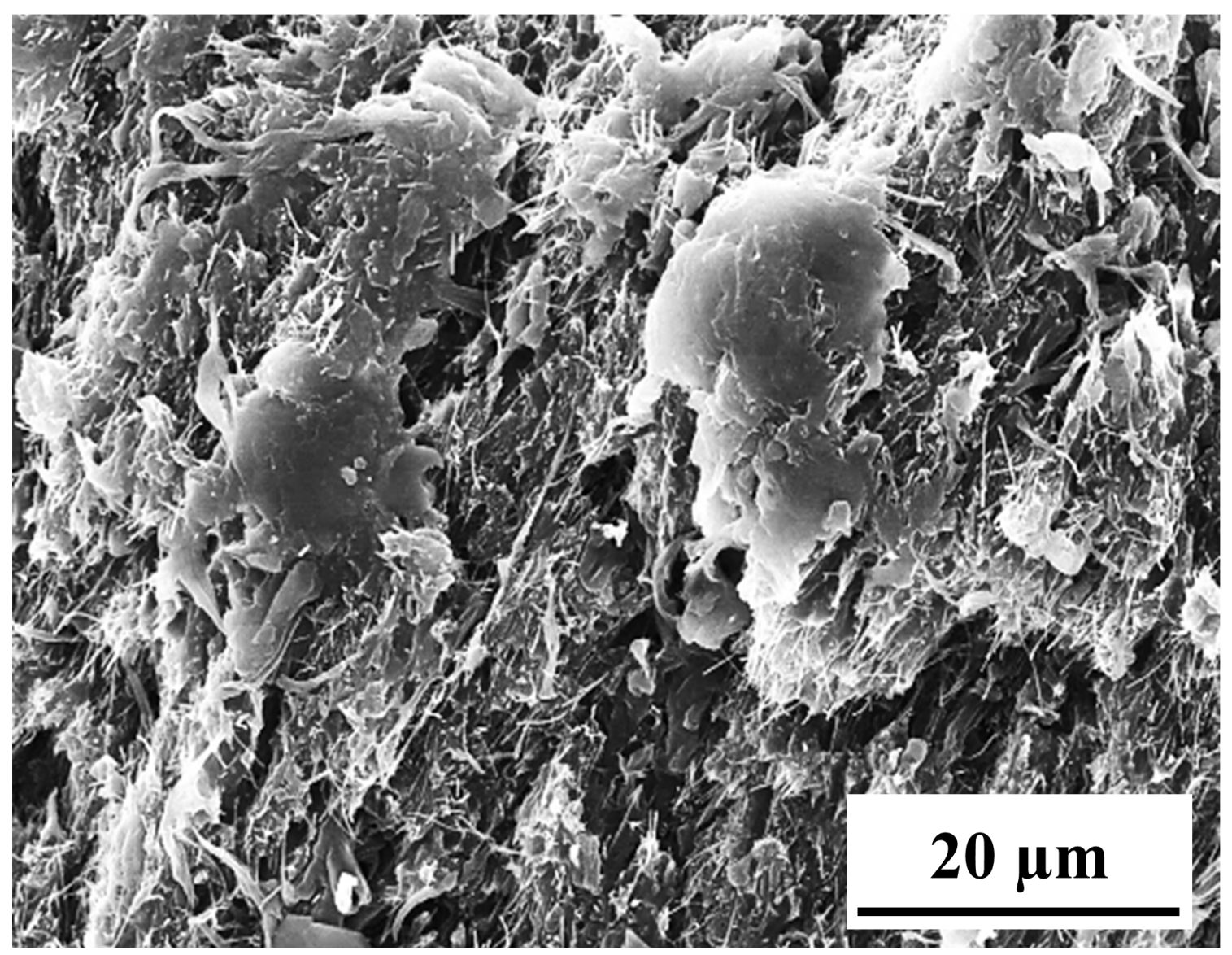

Rujirek et al., Fig. 5 


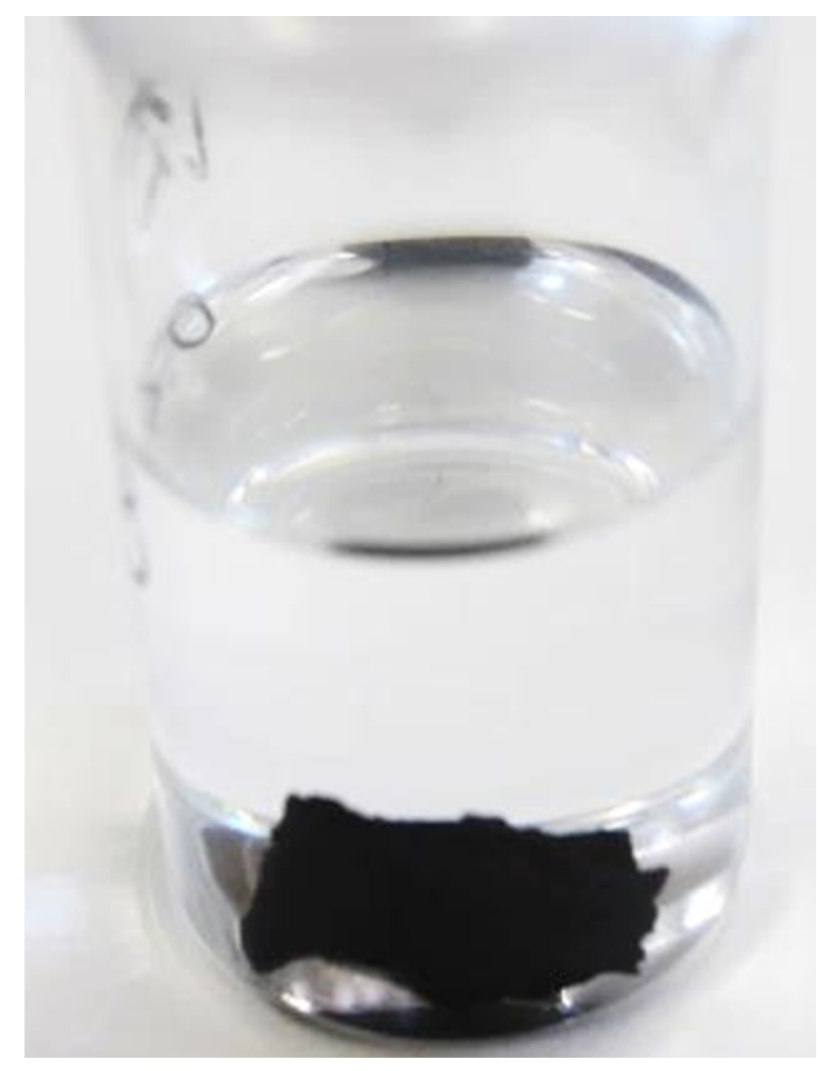

Rujirek et al., Fig. 6 


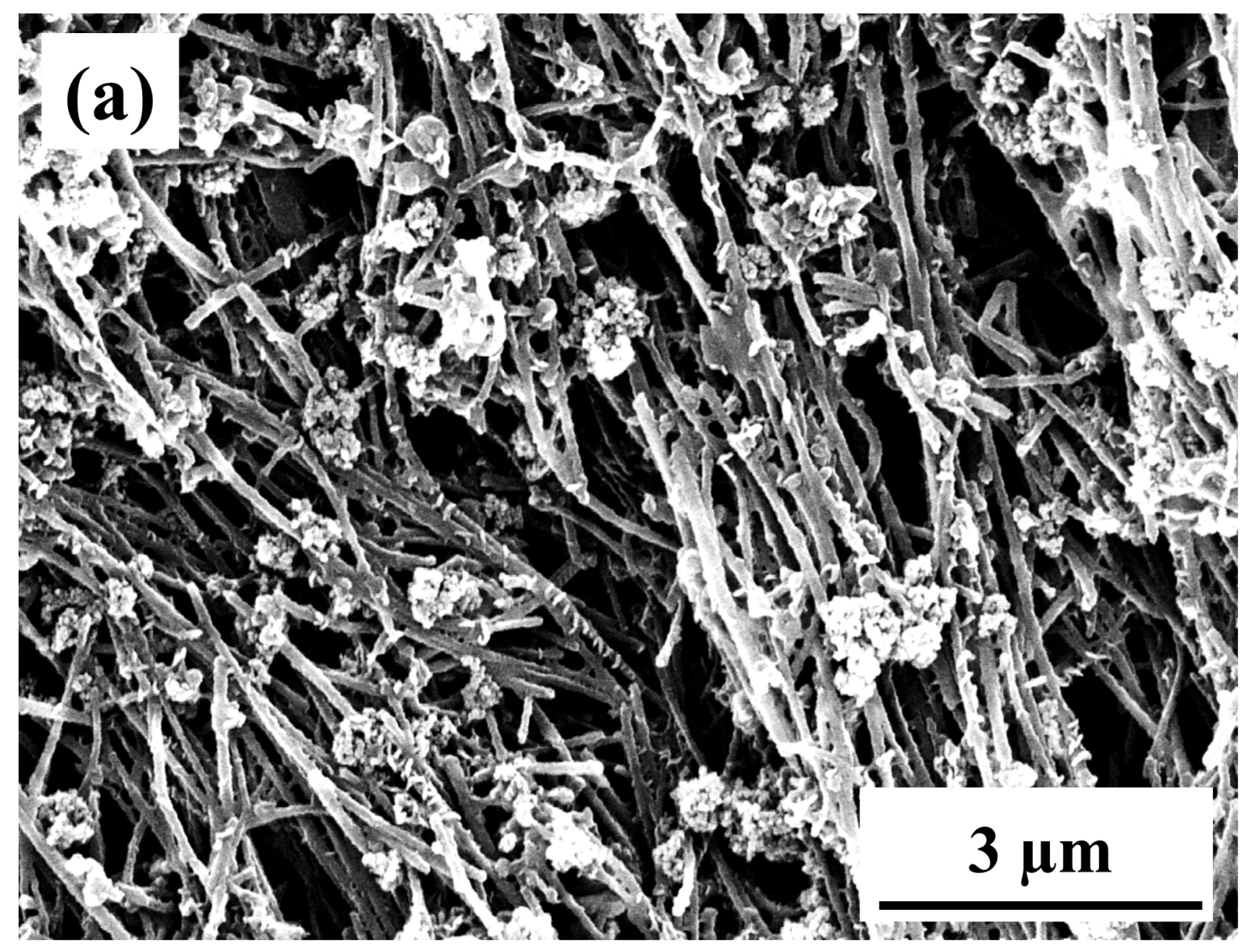

Rujirek et al., Fig. 7(a) 


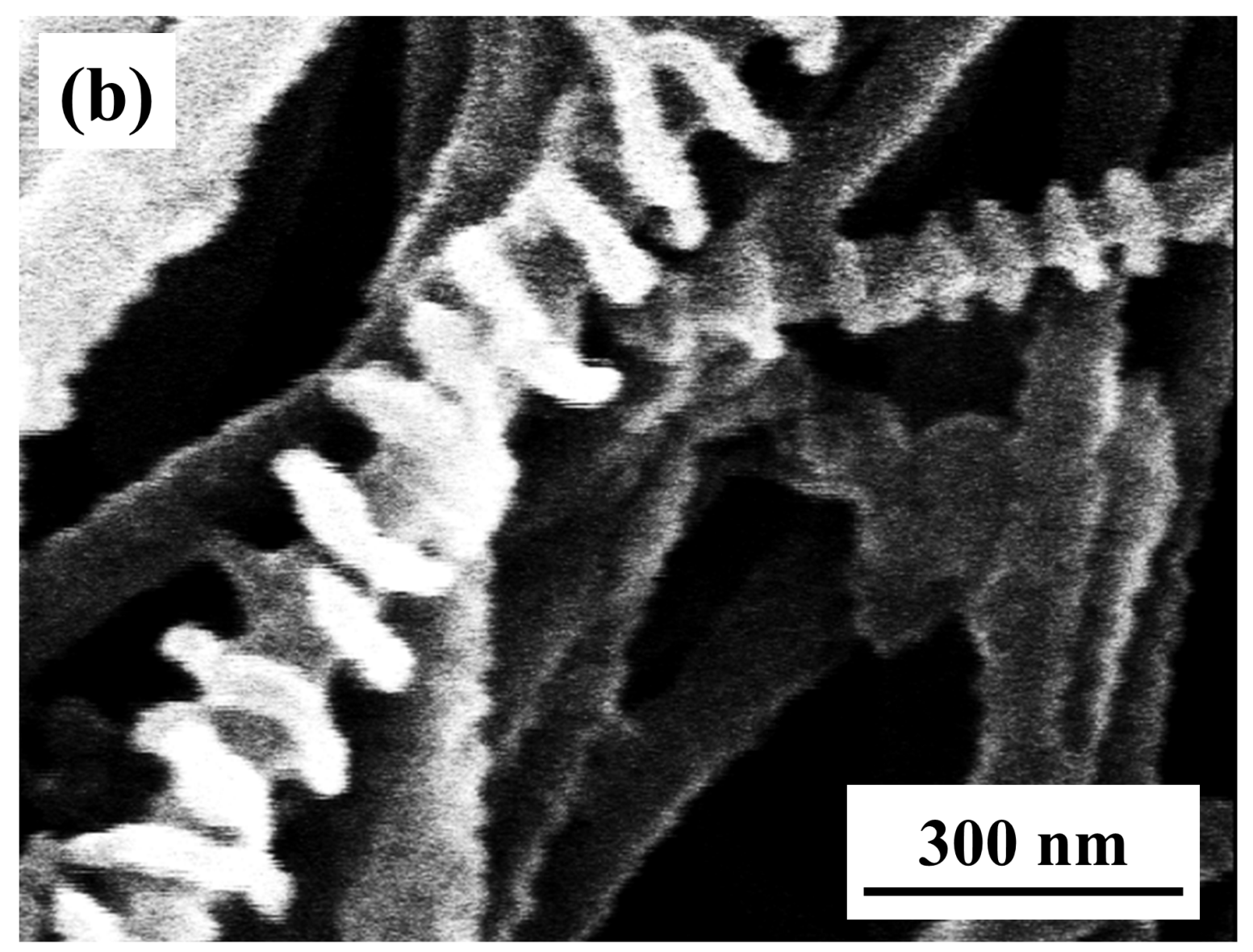

Rujirek et al., Fig. 7(b) 